\title{
INICIAÇÃO À DOCÊNCIA EM GEOGRAFIA, UM MODO DE FAZER: A TRAJETÓRIA DO PIBID/GEOGRAFIA NA UFFS
}

| | | | | | | | | | | | | | | | | | | | | | | | | | | | | | | | | | | | | | | | | | | | | | | | | | | | | | | | | | | | | | | | | | | | | | | | | | | | | | | | | | | | | | | | | | | | | | | | | | | | | | | | | | | | | | | | | | | | | | | | | | | | | | | | |

\author{
Ederson Nascimento ${ }^{1}$ \\ Aline Beatriz Ludwig ${ }^{2}$ \\ Márcio Freitas Eduardo ${ }^{3}$ \\ Ana Maria de Oliveira Pereira ${ }^{4}$ \\ Marlon Brandt ${ }^{5}$
}

\section{RESUMO}

Este texto tem por objetivo apresentar um panorama da metodologia de trabalho desenvolvida e das principais contribuições

1 Doutor em Geografia. Professor adjunto na Universidade Federal da Fronteira Sul (UFFS), coordenador de área do PIBID-UFFS, Subprojeto de Geografia (Campus Chapecó/SC). Contato: ederson.nascimento@uffs.edu.br

2 Mestra em Geografia. Professora na Rede Municipal de Educação de Chapecó. Contato: ludwig.aline@gmail.com

${ }^{3}$ Doutor em Geografia. Professor adjunto da Universidade Federal da Fronteira Sul (UFFS), coordenador de área do PIBID/UFFS, Subprojeto de Geografia (Campus Erechim/RS). Contato: marcioeduardo@uffs.edu.br

${ }^{4}$ Doutora em Diversidade e Inclusão. Professora adjunta da Universidade Federal da Fronteira Sul (UFFS). Coordenadora de área do PIBID-UFFS, Subprojeto de Geografia (Campus Erechim/RS). Contato: ana.pereira@uffs.edu.br

${ }^{5}$ Doutor em História. Professor adjunto na Universidade Federal da Fronteira Sul (UFFS), coordenador de área do PIBID-UFFS, Subprojeto de Geografia (Campus Chapecó/SC). Contato: marlon.brandt@uffs.edu.br 
empreendidas no âmbito do Subprojeto de Geografia do Programa Institucional de Bolsas de Iniciação à Docência na Universidade Federal da Fronteira Sul (UFFS), para a formação acadêmica e profissional dos licenciandos.

Palavras-chave: Ensino de Geografia. Iniciação à Docência. Formação docente. PIBID

\section{CONSIDERAÇÕES INICIAIS}

No âmbito da Geografia Escolar, o processo de iniciação à docência visa a criar oportunidades e condições para uma inserção, o mais antecipada e duradoura possível, de acadêmicos de cursos de Licenciatura em Geografia na práxis docente na Educação Básica. Tal processo tem tido ampliadas suas potencialidades com o advento do Programa Institucional de Iniciação à Docência (PIBID). No presente ensaio, apresenta-se um panorama da metodologia de trabalho desenvolvida e das principais contribuições empreendidas no âmbito do Subprojeto de Geografia do PIBID da Universidade Federal da Fronteira Sul (UFFS), para a formação acadêmica e profissional dos licenciandos.

O texto está organizado em duas partes. Na primeira seção, discute-se a importância da Geografia escolar para a formação pessoal e para o exercício da cidadania, considerando a potencialidade dos conhecimentos geográficos como subsídio à compreensão das dinâmicas do espaço socialmente (re)produzido. Na segunda parte, o foco se volta para a trajetória do PIBID nos cursos de Geografia da UFFS, em Chapecó/SC e Erechim/ $\mathrm{RS}$, procedendo-se, num primeiro momento, uma caracterização histórica do Programa e, em seguida, uma análise crítica de seus impactos sobre a formação docente. 


\section{REFLETINDO SOBRE A INICIAÇÃO À DOCÊNCIA EM GEOGRAFIA}

Muito antes de chegar à escola a criança já interage com o mundo, reconhece alguns lugares, porém ainda não o compreende na sua totalidade. Pelo simples fato de a criança caminhar, correr, brincar, ela já interage com o espaço, e aos poucos passa a reconhecer suas complexidades. $\mathrm{Na}$ escola, a Geografia tem o papel de fazer com que o aluno se reconheça no espaço na sua própria constituição e na sociedade que faz parte, enquanto cidadão atuante.

A Geografia é a disciplina que possibilita decodificar a realidade sob o olhar espacial, na medida em que o aluno contrapõe o conhecimento que ele traz consigo aos conceitos cientificamente elaborados, produzindo então o seu próprio conhecimento (CALLAI, 2003). Nesse sentido, deve-se considerar que o currículo escolar não é estático, pois a Geografia deve possibilitar a decodificação da realidade. Como a realidade se modifica, a Geografia precisa estar atualizada, os conteúdos podem e devem ser substituídos à medida que ocorrem mudanças na realidade e no mundo.

Callai (2003) aponta com clareza três motivos para estudar Geografia:

Primeiro: para conhecer o mundo e obter informações que há muito tempo é o motivo principal para estudar Geografia. Segundo: podemos acrescer que a Geografia é a ciência que estuda, analisa e tenta explicar o espaço produzido pelo homem. Terceira razão: não é o conteúdo em si, mas um objetivo maior que dá conta de tudo o mais, qual seja, a formação do cidadão. (CALLAI, 2003, p. 57).

A mesma autora acrescenta que além de uma disciplina que permite ser um instrumento útil para ler e entender o mundo e 
formar cidadãos, ela cria condições que possibilita o exercício da cidadania, esta, um processo construído culturalmente e historicamente (CALLAI, 2003). Formar o cidadão na contemporaneidade implica, necessariamente, incentivar a leitura crítica do mundo, contribuindo para que os estudantes tomem consciência do movimento dialético/contraditório da realidade que estão inseridos. Nas palavras de Santos (2000), o não cidadão se constitui na redução do cidadão a um mero usuário que aceita ser chamado de consumidor.

A educação não tem como objeto real armar o cidadão para uma guerra, a da competição com os demais. Sua finalidade, cada vez menos buscada e menos atingida, é a de formar gente capaz de se situar corretamente no mundo e de influir para que se aperfeiçoe a sociedade humana como um todo. A educação feita mercadoria reproduz e amplia as desigualdades, sem extirpar as mazelas da ignorância. Educação apenas para a produção setorial, educação apenas profissional, educação apenas consumista, cria, afinal, gente deseducada para a vida. (SANTOS, 2000, p. 126).

No entanto, esse processo tem se tornado cada vez mais complexo. Em um cenário de crise, não somente da conjuntura educacional, mas também no âmbito social, econômico e político, a promoção de políticas de desenvolvimento das capacidades individuais com vistas a uma sociedade com melhor qualidade de vida e de trabalho ficam, em geral, comprometidas. A escola, resultado dessa crise, somente reproduz o que está no cerne da modelo econômico vigente, desigualdades, competitividade e a dificuldade de pensar e agir em prol do coletivo na busca de realidades menos excludentes.

"Podemos compreender o espaço geográfico através do espaço escolar, pois é um (sub)espaço geográfico." (CASTROGIOVANNI, 2014, p. 87). Nesse sentido, as diferentes transformações 
da contemporaneidade em todos os aspectos da vida cotidiana vêm exigindo da educação um repensar constante e contínuo em relação aos cursos de formação e às práticas educativas. Como afirma Callai (2003, p. 27), "Hoje, estamos vivendo um processo de mudanças aceleradas, que modifica os contornos dos territórios nacionais como fruto de novas relações sociais, econômicas e políticas". Com isso, as disciplinas escolares recebem constantes atualizações de informações e a disciplina de Geografia se destaca nesse sentido, ao receber informações dos mais diversos espaços geográficos.

Formar professores dentro de uma perspectiva crítica, que se harmonize com o desenvolvimento de um processo de ensino e aprendizagem aberto às transformações pelas quais a sociedade contemporânea vem passando, é desafio premente para os cursos de licenciatura. É nesse contexto, que se situa a formação do professor de Geografia, haja vista que ao ensinar Geografia na escola básica, esse docente trabalha com a ciência geográfica, conhecimento decorrente das diversas relações socioespaciais, as quais operam produzindo o espaço geográfico. Entendemos que o processo de ensinar Geografia na Educação Básica é complexo e os cursos para formação de professores precisam possibilitar o aprofundamento do conhecimento teórico e da prática docente, no intuito de favorecer ao licenciandos, o entendimento da complexidade social no modo de produção capitalista, o que se torna importante para qualificar o ensino e a aprendizagem no espaço escolar.

Uma gama de fatores tem dificultado e influenciado negativamente a formação docente em muitas instituições de nível superior para atender a sociedade atual, por exemplo, déficit de professores, limitações na estrutura física, escassez de material e recursos humanos nas universidades, currículos defasados que não atendem as demandas atuais, desvalorização da carreira docente, escolas sucateadas, falta ou precariedade de laboratórios, 
dentre outros. Diante desse quadro, buscamos apresentar contribuições do Subprojeto PIBID de Geografia da UFFS, para a qualificação e formação dos futuros professores.

O Programa possibilita aos acadêmicos vivenciarem e conhecerem experiências do cotidiano escolar, qualificando-se para o exercício da profissão de professor. Por sua vez, os professores e o próprio espaço escolar da rede pública contribuem atuando como coformadores dos licenciandos. Essa sintonia oportuniza um novo olhar para a formação de professores, distanciando-se da ideia de que a teoria está na universidade e a prática no espaço escolar. Para as instituições educativas de Ensino Superior, o PIBID fortalece a integração com a Educação Básica e cria espaços de práxis.

Para Zeichner (2010), esse processo de iniciação dos licenciandos à docência pode ser reconhecido como um terceiro espaço na formação inicial de professores, superando a dualidade entre a formação acadêmica propriamente dita e a formação pela prática por si só. A criação de "terceiros espaços" na formação de professores envolve uma relação mais equilibrada e dialética entre o conhecimento acadêmico e o da prática profissional, a fim de dar apoio para aprendizagem dos professores em formação.

Romper com a lógica de que a universidade, detentora do conhecimento acadêmico, "legítimo", "superior", vai à escola para iluminá-la tem sido a tarefa empreendida. É fundamental para o sucesso do PIBID uma relação de diálogo igualitário entre todos os sujeitos envolvidos. Torna-se imprescindível a presença do(a) docente supervisor(a), conhecedor(a) do cenário escolar, que interage com os(as) acadêmicos(as) no calor dos acontecimentos.

Além disso, o PIBID reafirma nossa convicção de que ser professor não é um dom, pois a docência é uma profissão, possui uma base de conhecimento estabelecida na academia, e como qualquer outra profissão, demanda empenho, estudo, dedicação, responsabilidades e envolve propósitos sociais. 


\title{
OS CAMINHOS DO PIBID/GEOGRAFIA NA UFFS
}

\author{
A TRAJETÓRIA EM NÚMEROS E AÇÕES
}

O Subprojeto de Geografia da UFFS teve início em 2011 no Campus de Chapecó/SC, e no ano seguinte no Campus de Erechim/RS.

O núcleo de Chapecó teve início com dois coordenadores de área, seis licenciandos bolsistas e uma professora supervisora, atuando em uma escola parceira. No ano seguinte, o Subprojeto foi ampliado para mais uma escola, agregando outro docente e outros seis acadêmicos. De 2014 a 2018, em sua segunda fase, o Subprojeto teve um coordenador, dois supervisores e 12 licenciandos. Em Erechim, o início do PIBID contou com dois coordenadores, um docente supervisor e dez discentes bolsistas. Depois de 2014, o subprojeto, contou com a contribuição de outros três docentes coordenadores, com ampliação para três escolas participantes e o aumento para três no número de professores supervisores.

Até o início de 2018, participaram do Subprojeto Geografia nos dois campi 150 licenciandos, 11 supervisores e nove coordenadores de área, e milhares de alunos das escolas, tanto do Ensino Fundamental como do Ensino Médio, foram beneficiados. Coordenadores de área, docentes supervisores e bolsistas trabalham de modo articulado, desempenhando tarefas e atividades diferentes.

Em julho de 2018, o Subprojeto PIBID/Geografia da UFFS foi aprovado pelo processo seletivo regido pelos Editais n. 07/2018/Capes e n. 15/PROGRAD/UFFS/2018. No mês de agosto, foram iniciados os trabalhos na atual fase de desenvolvimento do Programa, com cada um dos núcleos contando com dois coordenadores, três supervisores e 24 licenciandos bolsistas, além de outros nove discentes voluntários (seis em Erechim e três em Chapecó). Um contingente expressivamente maior em relação aos editais anteriores! 
As atividades propostas aos licenciandos são elaboradas de acordo com os objetivos de cada subprojeto ${ }^{6}$, estes, por sua vez, sempre ancorados nos objetivos do PIBID da UFFS. Dentre as principais atividades desenvolvidas estão:

a) o conhecimento e acompanhamento da dinâmica escolar;

b) o desenvolvimento de grupos de estudos;

c) preparação e execução de atividades (intervenções em aula, oficinas, atividades de reforço escolar em períodos extraclasse, aulas de campo, entre outras);

d) atuação em sala de aula, que incluem a observação de aulas ministradas pelo(a) supervisor(a) e a ministração parcial de algumas aulas, e;

e) o registro e divulgação das atividades desenvolvidas.

O acompanhamento e conhecimento da dinâmica escolar visou ser o primeiro passo dos licenciandos dentro da escola. Neste momento, os futuros professores têm a função de observar o cotidiano e o funcionamento da escola, frequentar espaços escolares de relações que envolvam alunos e servidores, observar como são trabalhadas as questões pedagógicas, particularmente as referentes ao tratamento da disciplina Geografia no âmbito do Projeto Político Pedagógico, e acompanhar o professor supervisor em reuniões de professores, pais e conselhos de classe. Observam também o papel do professor de Geografia na escola e na sala de aula, acompanham a preparação de aulas, a escolha de materiais e sua respectiva utilização.

As reuniões no âmbito dos grupos de estudos correspondem a realizadas periodicamente nas dependências da universidade, e envolvem toda a equipe de cada um dos núcleos. Nesses momentos, realizam-se leituras dirigidas, apresentações de textos

${ }^{6}$ O subprojeto PIBID/Geografia apresentou três subprojetos distintos (em 2011, 2013 e 2018) em resposta a três diferentes processos de seleção de propostas institucionais empreendidos pela Capes, cada qual com objetivos específicos e critérios de elegibilidade distintos. 
e debates. Os textos selecionados para esses encontros estão relacionados à Educação Geográfica ou a Ciência Geográfica de um modo geral, juntamente com temas da atualidade. Esse também é o momento de trazer para o grupo as principais questões observadas da sua experiência na escola bem como das dificuldades encontradas a fim de compartilhar com grupo e encontrar soluções coletivamente.

A elaboração e execução das atividades consiste em uma das atividades mais complexas e ao mesmo tempo mais enriquecedoras para os futuros professores. A tarefa compreende a elaboração de atividades e/ou projetos de ensino de Geografia, seguindo o cronograma de conteúdos previsto pelo(a) supervisor(a), e quando finalizada é ministrada em sala de aula aos alunos da escola. Ao final de toda intervenção em sala, a avaliação da atividade e a autoavaliação por parte dos licenciandos se faz quase que de forma espontânea. Apontam-se as potencialidades, suas melhorias e o impacto para com os estudantes.

A todas as atividades envolvidas no projeto, sejam elas práticas e/ou teóricas, são sucedidas por um respectivo registro; toma-se nota das experiências e avaliações das atividades realizadas, sempre que possível inserindo imagens que posteriormente dão corpo à elaboração dos relatórios parciais e finais do projeto. Os resultados de algumas das atividades já propostas foram apresentados em produções científicas, como publicações de artigos em periódicos e apresentações (oral, banner) em eventos nacionais e internacionais ${ }^{7}$, além da elaboração de duas páginas disponíveis na internet, em formato de $b \log ^{8}$, onde são realizadas

\footnotetext{
7 Dentre as principais publicações oriundas das reflexões e atividades empreendidas no núcleo de Chapecó, pode-se mencionar: Ludwig et al. (2013), Nascimento et al. (2013), Nascimento e Ludwig (2015), Naibo et al. (2018) e Naibo, Graeff e Nascimento (2018).

8 PIBID Geografia-UFFS Chapecó/SC. Disponível em: < http://pibidgeouffs. blogspot.com/>. Acesso em: $10 \mathrm{ab}$ " eguirm que é desafiado a pensar.2019. PIBID
} 
postagens de atividades propostas e de trabalhos publicados, a fim de manter o registro e compartilhar experiências.

Aos professores supervisores cabe fazer a ponte entre os licenciandos e a escola, contribuir para a sua inserção e adaptação na comunidade escolar, participar da seleção de conteúdos e do planejamento das atividades a serem realizadas, colaborar na produção de textos científicos, produzir relatórios de acompanhamento das atividades dos bolsistas e participar das reuniões do grupo. De modo geral, o supervisor auxilia a coordenação de área na condução do subprojeto. Nessa tarefa, também está compreendida a realização das devidas articulações com a escola sobre a atuação e as práticas pedagógicas realizadas pelos bolsistas assim como comunicar a coordenação de área sobre possíveis problemas.

\section{OLHARES SOBRE A TRAJETÓRIA: IMPACTOS DO PIBID/GEOGRAFIA NA FORMAÇÃO DOCENTE}

São vários os potenciais impactos positivos do PIBID sobre a formação docente de modo geral, e na do (futuro) professor de Geografia em particular. Para melhor fundamentar empiricamente essa assertiva, pareceu importante dar voz a egressos do PIBID/Geografia que voluntariamente se dispuseram a responder um questionário virtual, organizado na plataforma Google Forms. O questionário foi enviado aos egressos do Programa via correio eletrônico, formado por questões de múltipla escolha relacionadas à vivência no Programa, sobre sua formação e atuação profissional. No quadro ${ }^{9}$ a seguir, destacamos algumas das perguntas mais relevantes para este estudo.

Geografia UFFS Erechim. Disponível em: http://pibidgeografiaerechim.blogspot.com/p/equipe_7.html. Acesso em: 11 abril 2019.

${ }^{9}$ O quadro representa um fragmento de uma pesquisa mais ampla, cuja análise completa será parte dos resultados de outro estudo, ora em preparação. 
Quadro 1 - Fragmento de questionário respondido por pibidianos egressos sobre o impacto do PIBID em sua formação acadêmica

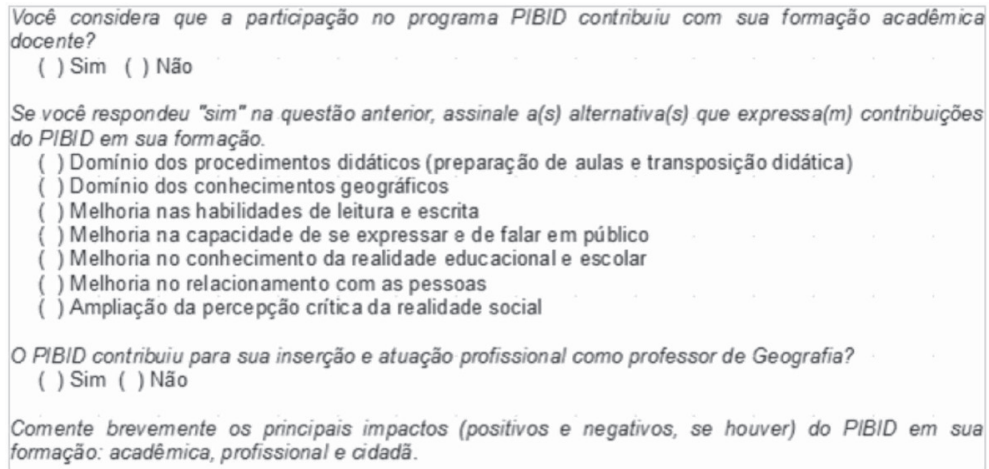

Fonte: Elaborado pelos autores

Todos os respondentes são unânimes em afirmar que a participação no PIBID contribuiu com sua formação acadêmica docente, sobretudo na inserção e atuação profissional como professor de Geografia. Os que ainda não estão atuando ou não concluíram a graduação expõem que os efeitos do PIBID já são percebidos no desenvolvimento de suas atividades de estágio curricular supervisionado.

Quando inquiridos sobre quais seriam as principais contribuições do PIBID para sua formação, alguns tópicos foram mais destacados, sugerindo a presença de algumas tendências. Todos os participantes da pesquisa assinalaram o domínio de procedimentos didáticos e a ampliação da percepção crítica da realidade social como as principais contribuições do Programa na sua formação. Com esse dado já é possível aferir que a contribuição do PIBID foi muito além de conteúdos, planos curriculares e procedimentos didáticos, uma vez que o desenvolvimento de um olhar crítico da sociedade da qual se está inserido não faz parte apenas da formação de um professor de Geografia, mas é parte, sobretudo, da formação de um cidadão. 
A melhoria na capacidade de se expressar publicamente e a melhoria no conhecimento da realidade escolar também foram destacadas significativamente como uma contribuição do PIBID para sua formação.

De outra parte, dizer que ao longo deste período o Subprojeto de Geografia teve apenas êxitos é uma inverdade. Todos aqueles que tiveram algum contato com o Programa, seja de Geografia ou outra área, sabem da sua importância na formação deste profissional tão nobre, o professor. Mas também são capazes de enumerar dificuldades ao longo do seu transcurso, a começar pela formação do grupo, encontrar uma escola que aceite o Programa, encontrar um professor supervisor que atenda as exigências dos editais não é tarefa fácil e, sobretudo, participar da convivência no âmbito do grupo que nem sempre é harmonioso.

O professor supervisor é o elo dos bolsistas com a escola e a sala de aula, uma peça da engrenagem imprescindível para o funcionamento do Programa e dos subprojetos, e sua importância é reiteradamente exaltada nas publicações e em eventos do Programa. No entanto, depois de atender as exigências do edital, é necessário ainda encontrar um professor que queira incluir em sua longa jornada de trabalho mais algumas tarefas e, acima de tudo, esteja disposto a contribuir efetivamente com a formação de futuros professores.

\section{REFLEXÕES FINAIS}

Ao longo de oito anos de atividades desenvolvidas no âmbito do PIBID, foi possível observar um maior domínio, por parte dos egressos, dos procedimentos didáticos bem como a ampliação da percepção crítica da realidade socioespacial, o que contribuiu não apenas na formação para a licenciatura e na construção de um olhar crítico da sociedade da qual se está inserido, mas 
também no desenvolvimento acadêmico, resultando em melhores relatórios de estágio, atividades de iniciação científica e mesmo nos trabalhos de conclusão de curso.

A partir de 2018, as mudanças empreendidas no Programa trouxeram novos desafios à organização de suas atividades. O aumento significativo no número de bolsistas (mínimo de 24) e a inclusão de acadêmicos voluntários, por exemplo, torna ainda mais complexa a articulação necessária a fim de mobilizar este expressivo contingente de licenciandos aptos a participar do Programa. Pois no caso específico dos cursos de Geografia de Chapecó e Erechim (assim como em outras licenciaturas da UFFS), a maioria dos estudantes também cumpre uma dupla, por vezes tripla jornada de atividades - no trabalho, no domicílio e na universidade -, dispondo, por isso, de tempo reduzido para participar do Programa.

Apesar disso, salientamos a importância desse efetivo de bolsas do PIBID para a vinculação de um número maior de licenciandos ao universo do ensino e da práxis docente na Educação Básica, desde o primeiro semestre do curso até o seu final ${ }^{10}$. Embora o valor da bolsa seja reduzido e esteja bastante defasado ${ }^{11}$, sua disponibilidade é de suma importância para os discentes, os quais ainda têm a possibilidade de complementar sua renda com vínculos empregatícios ou, em casos específicos, com recursos do Programa de auxílio socioassistencial da UFFS.

Por sua vez, a diminuição da carga horária mínima exigida para oito horas semanais, em relação aos editais precedentes,

\footnotetext{
10 A partir de 2018, com a criação do Programa Residência Pedagógica (PRP), as vagas do PIBID foram direcionadas somente para estudantes da primeira metade dos cursos de licenciatura, ficando os acadêmicos da segunda metade direcionados às vagas do PRP. Na UFFS, este último Programa também oferta 24 bolsas para cada um dos cursos de Geografia (Chapecó e Erechim).

11 O valor da bolsa de iniciação à docência, de $\mathrm{R} \$ 400,00$, segue inalterado desde 2011.
} 
se por um lado tornou possível o ingresso de um maior número de estudantes aptos a engajarem-se na iniciação à docência, por outro reduziu o tempo dos pibidianos, bem como o número de atividades conduzidas tanto no âmbito da universidade quanto no espaço escolar.

Para finalizar este ensaio, ressalta-se, uma vez mais, a importância do PIBID, não somente para a iniciação à docência stricto sensu dos licenciandos, mas também para os demais entes que dele participam. As experiências acumuladas pelos acadêmicos consistem em um importante ativo para o desenvolvimento de sua formação acadêmica e profissional bem como para o exercício da cidadania. Para os supervisores, a troca de experiências oportuniza-lhes também uma revalorização de seus conhecimentos docentes e a possibilidade de diversificar e enriquecer suas aulas. Com isso, por sua vez, ganham também os alunos das escolas, que podem ter ressignificado o seu processo de construção do conhecimento geográfico.

\section{REFERÊNCIAS}

CALLAI, Helena Copetti. O ensino de geografia: recortes espaciais para análise. In: CASTROGIOVANNI, Antonio Carlos et al. Geografia em sala de aula: práticas e reflexões. Porto Alegre: UFRGS, 2003. p. 57-63.

CASTROGIOVANNI, Antonio Carlos. Subir aos sótãos para descobrir a Geografia. In: MARTINS, Rosa Elisabete Militiz Wypyczynki et al (org.). Ensino de Geografia no contemporâneo: experiências e desafios. Santa Cruz do Sul: EDUNISC, 2014. p. 85-101.

LUDWIG, Aline Beatriz et al. Cartografia temática e ensino de Geografia: reflexões e experiências. In: ENCUENTRO DE GEÓGRAFOS DE AMÉRICA LATINA, 14., 2013, Lima. Anales [...] Lima: UGI, 2013. Disponível em: http:// 
observatoriogeograficoamericalatina.org.mx/egal14/

Ensenanzadelageografia/Metodologiaparalaensenanza/47.pdf. Acesso em: 29 mar. 2019.

NAIBO, Gerson J.; GRAEFF, Ademar; NASCIMENTO, Ederson. A cartografia tátil na formação docente em Geografia: uma experiência. In: ENCONTRO NACIONAL DE GEÓGRAFOS, 19., 2018, João Pessoa. Anais [...] João Pessoa: AGB, 2018. Disponível em: https:// www.researchgate.net/publication/329320022. Acesso em: 29 mar. 2019.

NAIBO, Gerson J. et al. A aula de campo como metodologia de ensinoaprendizagem de Geografia. In: ALVES, Solange Maria et al. (org.). PIBID UFFS: contribuições à formação docente. Toledo: Vivens, 2018. p. 137-148.

NASCIMENTO, Ederson; LUDWIG, Aline Beatriz. A educação cartográfica no ensino-aprendizagem de Geografia: reflexões e experiências. Geografia Ensino \& Pesquisa, Santa Maria, v. 19, n. 3, p. 29-42, set./dez. 2015.

NASCIMENTO, Ederson et al. Ensinando e aprendendo Geografia por meio de práticas pedagógicas não formais. In: MARASCHIN, Maria Lucia; FERREIRA, Jeferson Saccol; CAMBRUSSI, Morgana F. (org.). Iniciação à docência: experiências, significações e perspectivas. Curitiba: CRV, 2013. p. 67-78.

PIBID Geografia UFFS Chapecó. Portal virtual. [2019]. Disponível em: http://pibidgeouffs.blogspot.com/. Acesso em: 10 abr. 2019.

PIBID Geografia UFFS Erechim. Portal virtual. [2019]. Disponível em: http://pibidgeografiaerechim.blogspot.com/p/equipe_7.html. Acesso em: 11 abr. 2019.

SANTOS, Milton. O espaço do cidadão. 5. ed. São Paulo: Nobel, 2000.

ZEICHNER, Ken. Repensando as conexões entre a formação na universidade e as experiências de campo na formação de professores em faculdades e universidades. Educação, Santa Maria, v. 35, n. 3, p. 479-504, set./dez. 2010. 
